\title{
An improved non-dimensional model of wet-cooling towers
}

\author{
B A Qureshi and S M Zubair* \\ Mechanical Engineering Department, King Fahd University of Petroleum and Minerals, Dhahran, Saudi Arabia
}

The manuscript was received on 1 April 2005 and was accepted after revision for publication on 21 July 2005.

DOI: $10.1243 / 095440805 X 62205$

\begin{abstract}
A general non-dimensional mathematical model of cooling towers is improved by including evaporation of water. The solution still consists of adjusting the assumed straight air-saturation line to the real air-saturation data, but a new constant $(H)$ is added as well. Two solutions are proposed and the accuracy of each method is checked against data from the literature and also compared with the original solution. The first method shows a maximum decrease of 4.4 per cent in error, whereas in the second method, the maximum error was found to be 3.3 and 6.8 per cent when the inlet air was unsaturated and saturated, respectively.
\end{abstract}

Keywords: cooling tower, non-dimensional model, evaporation

\section{INTRODUCTION}

In cooling towers, a warm water stream is cooled through evaporation of some of the water into an air stream. These towers are often used in large thermal systems to reject the waste heat via a water loop between the two devices. One of the advantages of the cooling tower over the dry heat exchanger is that, through evaporation, the circulating water temperature may approach the atmospheric wetbulb temperature rather than the dry-bulb temperature and that cooling takes place through both heat- and mass-transfer mechanisms. There are several types of cooling towers. Probably, the most common is the mechanical draft tower in which the water enters at the top of the tower as a spray and flows downwards through the tower. Ambient air is drawn into the tower with the help of fans and flows in a counter or cross-current manner to the water stream. If the fans are at the bottom of the tower and blow the air upwards past the water flow, the tower is termed as a forced draft tower, whereas if the fans are at the top, it is an induced draft tower. Large-size atmospheric towers, e.g. at conventional or nuclear power plants, do not use a

*Corresponding author: Department of Mechanical Engineering, King Fahd University of Petroleum and Minerals, PO Box 1474, Dhahran 31261, Saudi Arabia. fan but rely on the buoyancy effect of the heated air and a nozzle-like (or hyperbolic) shape to cause air circulation. A typical schematic representation of a counterflow wet-cooling tower is shown in Fig. 1.

A basic theory of cooling tower operation was originally proposed by Walker et al. [1], but the practical use of the basic differential equations, however, was first presented by Merkel [2], in which the enthalpy difference was the driving potential. With the availability of fast and reliable computers, the governing differential equations can be solved numerically with a greater accuracy [3]. It is important to note that even after this, the Merkel model still remained in wide use, although various other detailed procedures and solutions for the design and rating of wet counterflow and cross-flow mechanical and natural draught cooling towers have been presented by various researchers [4-9]. However, Halasz [10] presented a general non-dimensional model that described all types of evaporative heat exchangers for counterflow, cross-flow, and parallel flow directions of water and air. The advantage of reducing the number of variables and the possibility of graphical representation of the results are evident. This general non-dimensional model was then applied specifically to cooling towers $[\mathbf{1 1}]$ where the efficiency was expressed as a function of only two variables and plotted in one figure for each type of cooling tower. It should be noted that various assumptions were employed, in which neglecting 


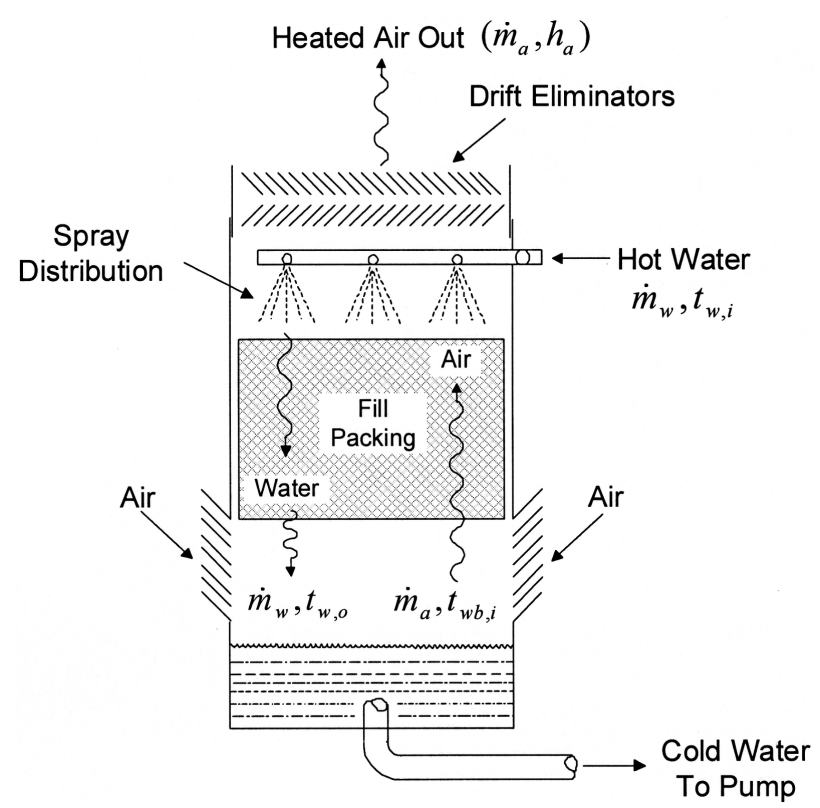

Fig. 1 Schematic representation of a counterflow wet cooling tower

water evaporation and adjusting the assumed straight air-saturation line to the real air-saturation data are prominent. The accuracy of the model was compared with the data available in the literature and was found to be good for normal operating conditions, failing only when the cooling range was very large or when the air flow rate was very small. Furthermore, the air was assumed to be unsaturated or, as a limiting case, saturated without fog.

The objective of this article is to improve the nondimensional model developed by Halasz [11] for wet-cooling towers. In this regard, the assumption of constant water mass flow rate is neglected and the derivation is repeated to obtain a more accurate analytical solution by introducing another constant in the mathematical model; then, two possible methods are proposed to obtain its value.

\section{LIST OF ASSUMPTIONS}

The following basic assumptions are relevant to the mathematical model and to the general closedform solution that is found subsequently.

1. The process is steady state.

2. The cooling tower is insulated.

3. Mass flow rates and inlet thermal states are constant in a plane perpendicular to the direction of flow of respective fluids. If no crossflow occurs in the device, then it is similarly assumed constant for all other thermal states, not only the inlet ones.
4. Longitudinal heat conduction is neglected along the wall and inside the fluids in their direction of flow.

5. Water-air interface temperature is assumed to be equal to the bulk water temperature.

6. All the coefficients in the non-dimensional differential equations are constants; that is, thermal properties of air, water, and process fluids, heatand mass-transfer coefficients, and their combinations in non-dimensional equations.

7. Saturated humidity ratio is a linear function of temperature.

8. The second term in parentheses of equation (29), representing the dimensionless mass-transfer potential, is neglected because it is small compared with unity.

9. Air is unsaturated in the whole process unless otherwise indicated.

Presently, the assumption of constant water flow rate made by Halasz $[\mathbf{1 0}, \mathbf{1 1}]$ is neglected and the general non-dimensional equations are derived again for an improved non-dimensional model.

\section{MATHEMATICAL MODEL}

An infinitesimal control volume of a wet-cooling tower associated with the differential area $\mathrm{d} A$ is presented in Fig. 2. All assumptions, which were used by Halasz $[\mathbf{1 0}, 11]$ to derive the modelling equations, have been summarized in section 2. It should be noted that all these were employed here as well except for the assumption of constant water flow rate, which is the focus of the current work. In addition, it is also considered that no cross-flow occurs, so as to deal with ordinary differential equations.

\subsection{Energy and mass balance: subsystem I - air}

The airside water-vapour mass balance (Fig. 2) gives

$$
\dot{m}_{\mathrm{a}} \mathrm{d} W=h_{\mathrm{D}}\left(W_{\mathrm{s}, \text { int }}-W\right) \mathrm{d} A
$$

Expressing the air energy balance in terms of heatand mass-transfer coefficients, $h_{\mathrm{c}}$ and $h_{\mathrm{D}}$, respectively, for the case $h_{\mathrm{fg} \text {,int }} \approx h_{\mathrm{g} \text {, int }}$

$$
\dot{m}_{\mathrm{a}} \mathrm{d} h=h_{\mathrm{c}}\left(t_{\text {int }}-t\right) \mathrm{d} A+h_{\mathrm{D}} \mathrm{d} A\left(W_{\mathrm{s}, \text { int }}-W\right) h_{\mathrm{g}, \text { int }}
$$

\subsection{Energy and mass balance: subsystem II - water}

The mass flow of recirculating water evaporating into air, in terms of the mass-transfer coefficient, $h_{\mathrm{D}}$, can 


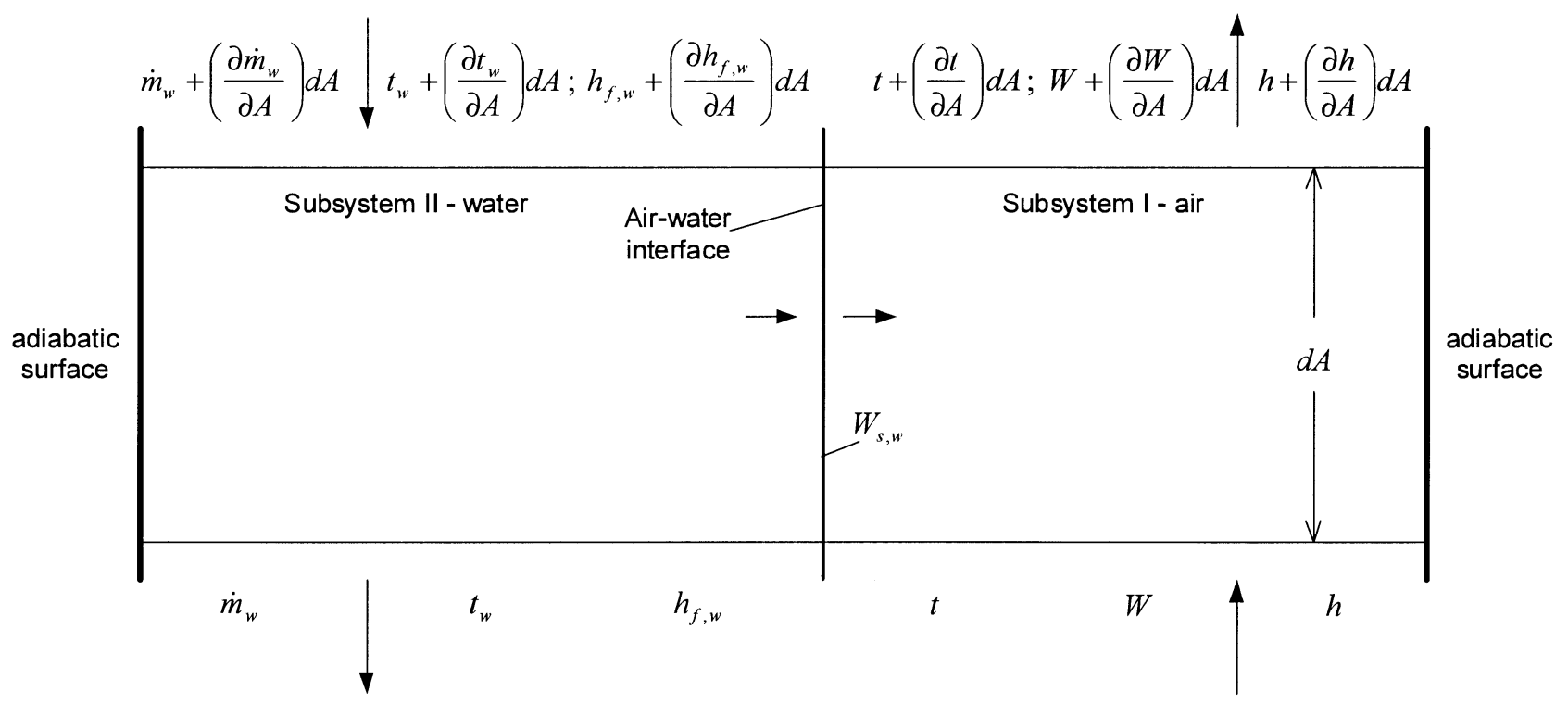

Fig. 2 Control volume of a counterflow wet cooling tower

be written as

$$
\mathrm{d} \dot{m}_{\mathrm{w}}=-h_{\mathrm{D}}\left(W_{\mathrm{s}, \text { int }}-W\right) \mathrm{d} A
$$

Expressing the water energy balance in terms of heat- and mass-transfer coefficients, $h_{\mathrm{c}}$ and $h_{\mathrm{D}}$, respectively

$$
\begin{aligned}
\dot{m}_{\mathrm{w}} h_{\mathrm{f}, \mathrm{w}}= & \left(\dot{m}_{\mathrm{w}}+\mathrm{d} \dot{m}_{\mathrm{w}}\right)\left(h_{\mathrm{f}, \mathrm{w}}+\mathrm{d} h_{\mathrm{f}, \mathrm{w}}\right)+h_{\mathrm{c}}\left(t_{\mathrm{int}}-t\right) \mathrm{d} A \\
& +h_{\mathrm{D}} \mathrm{d} A\left(W_{\mathrm{s}, \text { int }}-W\right)\left(h_{\mathrm{g}, \mathrm{int}}-h_{\mathrm{f}, \mathrm{w}}\right)
\end{aligned}
$$

Neglecting the higher order term on the RHS and substituting equation (3), after simplification results in

$$
\begin{aligned}
\dot{m}_{\mathrm{w}} \mathrm{d} h_{\mathrm{f}, \mathrm{w}}= & -h_{\mathrm{c}}\left(t_{\text {int }}-t\right) \mathrm{d} A \\
& -h_{\mathrm{D}} \mathrm{d} A\left(W_{\mathrm{s}, \text { int }}-W\right)\left(h_{\mathrm{g}, \text { int }}-2 h_{\mathrm{f}, \mathrm{w}}\right)
\end{aligned}
$$

\subsection{Governing differential equations}

The change in water enthalpy can be written in terms of specific heat as

$$
\mathrm{d} h_{\mathrm{f}, \mathrm{w}}=c_{\mathrm{p}, \mathrm{w}} \mathrm{d} t_{\mathrm{w}}
$$

For a negligible temperature difference between the bulk water and water-air interface $[5, \mathbf{1 2}]$, it is assumed that

$$
t_{\text {int }}=t_{\mathrm{w}} \quad \text { and } \quad W_{\mathrm{s}, \text { int }}=W_{\mathrm{s}, \mathrm{w}}
$$

Substituting equations (6) and (7) into equations (1) to (3) and (5), the following system of equations is obtained

$$
\begin{aligned}
\dot{m}_{a} \mathrm{~d} W= & h_{\mathrm{D}}\left(W_{\mathrm{s}, \mathrm{w}}-W\right) \mathrm{d} A \\
\dot{m}_{\mathrm{a}} \mathrm{d} h= & h_{\mathrm{c}}\left(t_{w}-t\right) \mathrm{d} A+h_{\mathrm{D}} \mathrm{d} A\left(W_{\mathrm{s}, \mathrm{w}}-W\right) h_{\mathrm{g}, \mathrm{w}} \\
\mathrm{d} \dot{m}_{\mathrm{w}}= & -h_{\mathrm{D}}\left(W_{\mathrm{s}, \mathrm{w}}-W\right) \mathrm{d} A \\
\dot{m}_{\mathrm{w}} c_{\mathrm{p}, \mathrm{w}} \mathrm{d} t_{\mathrm{w}}= & -h_{\mathrm{c}}\left(t_{\mathrm{w}}-t\right) \mathrm{d} A-h_{\mathrm{D}} \\
& \times \mathrm{d} A\left(W_{\mathrm{s}, \mathrm{w}}-W\right)\left(h_{\mathrm{fg}, \mathrm{w}}-h_{\mathrm{f}, \mathrm{w}}\right)
\end{aligned}
$$

It should be noted that Halasz $[\mathbf{1 0}, \mathbf{1 1}]$ neglected equation (10) and considered the water flow rate as constant. In the current work, this equation is maintained and it is the basis of improving the nondimensional mathematical model applied to cooling towers.

\subsection{Non-dimensional variables}

The non-dimensional air and water temperatures, using the difference of the inlet dry- and wet-bulb air temperatures, can be expressed as [10]

$$
\Theta_{\mathrm{a}}=\frac{t-t_{\mathrm{wb}, \mathrm{i}}}{t_{\mathrm{db}, \mathrm{i}}-t_{\mathrm{wb}, \mathrm{i}}} ; \quad \Theta_{\mathrm{w}}=\frac{t_{\mathrm{w}}-t_{\mathrm{wb}, \mathrm{i}}}{t_{\mathrm{db}, \mathrm{i}}-t_{\mathrm{wb}, \mathrm{i}}}
$$

Similarly, the non-dimensional humidity ratios are

$$
\xi_{\mathrm{a}}=\frac{W-W_{\mathrm{s}, \mathrm{wb}}}{W_{\mathrm{s}, \mathrm{wb}}-W_{\mathrm{i}}} ; \quad \xi_{w}=\frac{W_{\mathrm{s}, \mathrm{w}}-W_{\mathrm{s}, \mathrm{wb}}}{W_{\mathrm{s}, \mathrm{wb}}-W_{\mathrm{i}}}
$$


The denominators in equations (12) and (13) are related by $[\mathbf{1 3}]$

$$
\begin{aligned}
t_{\mathrm{db}, \mathrm{i}}-t_{\mathrm{wb}, \mathrm{i}} & =\frac{h_{\mathrm{D}} h_{\mathrm{fg}, \mathrm{wb}}}{h_{\mathrm{c}}}\left(W_{\mathrm{s}, \mathrm{wb}}-W_{\mathrm{i}}\right) \\
& =\frac{h_{\mathrm{D}} c_{\mathrm{p}, \mathrm{a}}}{h_{\mathrm{c}}} \frac{h_{\mathrm{fg}, \mathrm{wb}}}{h_{\mathrm{c}} c_{\mathrm{p}, \mathrm{a}}}\left(W_{\mathrm{s}, \mathrm{wb}}-W_{\mathrm{i}}\right)
\end{aligned}
$$

The transformation of equation (8) into a nondimensional form, using equation (13) and introducing Lewis relation defined by Halasz $[\mathbf{1 0}]$ as $L e=h_{\mathrm{D}} c_{\mathrm{p}, \mathrm{a}} / h_{\mathrm{c}}$, gives

$$
\frac{\mathrm{d} \xi_{a}}{\mathrm{~d} X}=L e\left(\xi_{\mathrm{s}, \mathrm{w}}-\xi_{\mathrm{a}}\right)
$$

where the dimensionless (common) variable $X(0 \leqslant$ $X \leqslant X_{0}$ ) is defined as

$$
X=\frac{h_{\mathrm{c}} A}{\dot{m}_{\mathrm{a}} c_{\mathrm{p}, \mathrm{a}}}
$$

Another important relationship due to an extra variable present in equation (15) can be introduced by combining equations (12) to (14) and using the non-dimensional relationships of $\Theta_{\mathrm{w}}$ and $\xi_{\mathrm{s}, \mathrm{w}}$. The resulting equation is easily obtained and is given by [10]

$$
\xi_{\mathrm{s}, \mathrm{w}}=\frac{h_{\mathrm{D}} h_{\mathrm{fg}, \mathrm{wb}}}{h_{\mathrm{c}}} \frac{W_{\mathrm{s}, \mathrm{w}}-W_{\mathrm{s}, \mathrm{wb}}}{t_{\mathrm{w}}-t_{\mathrm{wb}, \mathrm{i}}} \Theta_{\mathrm{w}}
$$

As the objective is to obtain a purely nondimensional model, the undesirable terms in equation (17) may be removed. For this purpose, Halasz [10] replaced the real air-saturation line by a straight air saturation line using the relationships

$$
W_{\mathrm{s}, \mathrm{w}}=a+b t_{\mathrm{w}} \quad \text { and } \quad W_{\mathrm{s}, \mathrm{wb}}=a+b t_{\mathrm{wb}, \mathrm{i}}
$$

Simplifying, the following parameter is obtained

$$
b=\frac{W_{\mathrm{s}, \mathrm{w}}-W_{\mathrm{s}, \mathrm{wb}}}{t_{\mathrm{w}}-t_{\mathrm{wb}, \mathrm{i}}}
$$

It is important to note that this linearization process did not introduce a large error because only a small section of the saturation line is relevant, i.e. between $t_{\mathrm{w}, \mathrm{i}}$ and $t_{\mathrm{w}, \mathrm{o}}$. Thus, the substitution of equation (19) into equation (17) gives

$$
\xi_{\mathrm{s}, \mathrm{w}}=\frac{h_{\mathrm{D}} c_{\mathrm{p}, \mathrm{a}}}{h_{\mathrm{c}}} \frac{b h_{\mathrm{fg}, \mathrm{wb}}}{c_{\mathrm{p}, \mathrm{a}}} \Theta_{\mathrm{w}}=B L e \Theta_{\mathrm{w}}
$$

where

$$
B=\frac{b h_{\mathrm{fg}, \mathrm{wb}}}{c_{\mathrm{p}, \mathrm{a}}}
$$

It should be noted that the values of $h_{\mathrm{fg}, \mathrm{wb}}$ and $c_{\mathrm{p}, \mathrm{a}}$ can be calculated by using the following relationships

$$
\begin{aligned}
& h_{\mathrm{fg}, \mathrm{wb}}=h_{\mathrm{g}}^{0}+\left(c_{\mathrm{p}, \mathrm{v}}-c_{\mathrm{p}, \mathrm{w}}\right) t_{\mathrm{wb}, \mathrm{i}} \\
& c_{\mathrm{p}, \mathrm{a}}=c_{\mathrm{p}, \mathrm{da}}+W c_{\mathrm{p}, \mathrm{v}} \cong c_{\mathrm{p}, \mathrm{da}}+W_{\mathrm{s}, \mathrm{wb}} c_{\mathrm{p}, \mathrm{v}}
\end{aligned}
$$

An important point here is that $b$ and $B$ are variables, but, to obtain an analytical solution, these were considered as constant (representative) values as recognized by Halasz [10] and in the current work. The procedure for finding the value of these parameters is explained in Appendix 3. Finally, substituting equation (20) into equation (15), gives

$$
\frac{\mathrm{d} \xi_{\mathrm{a}}}{\mathrm{d} X}=-L e\left(\xi_{\mathrm{a}}-B L e \Theta_{\mathrm{w}}\right)
$$

To transform equation (9) into a non-dimensional form, the moist air enthalpy is considered as [13]

$$
h=c_{\mathrm{p}, \mathrm{da}} t+W\left(h_{\mathrm{g}}^{0}+c_{\mathrm{p}, \mathrm{v}} t\right)
$$

The derivative of equation (25) gives

$$
\frac{\mathrm{d} h}{\mathrm{~d} A}=\left(c_{\mathrm{p}, \mathrm{da}}+W c_{\mathrm{p}, \mathrm{v}}\right) \frac{\mathrm{d} t}{\mathrm{~d} A}+\left(h_{\mathrm{g}}^{0}+c_{\mathrm{p}, \mathrm{v}} t\right) \frac{\mathrm{d} W}{\mathrm{~d} A}
$$

Noting that

$$
h_{\mathrm{g}, \mathrm{w}}=h_{\mathrm{g}}^{0}+c_{\mathrm{p}, \mathrm{v}} t_{\mathrm{w}}
$$

and substituting equations (23) and (27), as well as $(\mathrm{d} h / \mathrm{d} A)$ from equation (9) and $(\mathrm{d} W / \mathrm{d} A)$ from equation (8) into equation (26), results in

$$
\begin{gathered}
\frac{h_{\mathrm{c}}}{\dot{m}_{\mathrm{a}}}\left(t_{\mathrm{w}}-t\right)+\frac{h_{\mathrm{D}}}{\dot{m}_{\mathrm{a}}}\left(W_{\mathrm{s}, \mathrm{w}}-W\right)\left(h_{\mathrm{g}}^{0}+c_{\mathrm{p}, \mathrm{v}} t_{\mathrm{w}}\right) \\
=\left(c_{\mathrm{p}, \mathrm{da}}+W c_{\mathrm{p}, \mathrm{v}}\right) \frac{\mathrm{d} t}{\mathrm{~d} A}+\left(h_{\mathrm{g}}^{0}+c_{\mathrm{p}, \mathrm{v}} t\right) \\
\quad \times \frac{h_{\mathrm{D}}}{\dot{m}_{\mathrm{a}}}\left(W_{\mathrm{s}, \mathrm{w}}-W\right)
\end{gathered}
$$

Simplifying

$$
\frac{\mathrm{d} t}{\mathrm{~d} A}=\frac{h_{\mathrm{c}}}{\dot{m}_{\mathrm{a}} c_{\mathrm{p}, \mathrm{a}}}\left(t_{\mathrm{w}}-t\right)\left[1+\frac{h_{\mathrm{D}} c_{\mathrm{p}, \mathrm{a}}}{h_{\mathrm{c}}} \frac{c_{\mathrm{p}, \mathrm{v}}}{c_{\mathrm{p}, \mathrm{a}}}\left(W_{\mathrm{s}, \mathrm{w}}-W\right)\right]
$$

Halasz [10] assumed the value of terms in parenthesis to be 1 , resulting in an error of only a few per 
cent for the air temperature change, which simplified the aforementioned equation and the subsequent transformation. Now, applying equations (12) and (16), the aforementioned equation can be written as

$$
\frac{\mathrm{d} \Theta_{\mathrm{a}}}{\mathrm{d} X}=\left(\Theta_{\mathrm{w}}-\Theta_{\mathrm{a}}\right)
$$

Finally, the non-dimensional form of equation (11) can be obtained by applying equations (12) and (13) and then simplifying

$$
\begin{aligned}
\dot{m}_{\mathrm{w}} c_{\mathrm{p}, \mathrm{w}} & \frac{\mathrm{d} \Theta_{\mathrm{w}}}{\mathrm{d} A}\left(t_{\mathrm{db}, \mathrm{i}}-t_{\mathrm{wb}, \mathrm{i}}\right) \\
= & -h_{\mathrm{c}}\left[\left(\Theta_{\mathrm{w}}-\Theta_{\mathrm{a}}\right)\left(t_{\mathrm{db}, \mathrm{i}}-t_{\mathrm{wb}, \mathrm{i}}\right)\right]-h_{\mathrm{D}}\left[\left(\xi_{\mathrm{s}, \mathrm{w}}-\xi_{\mathrm{a}}\right)\right. \\
& \left.\times\left(W_{\mathrm{s}, \mathrm{wb}}-W_{\mathrm{i}}\right)\right]\left(h_{\mathrm{fg}, \mathrm{w}}-h_{\mathrm{f}, \mathrm{w}}\right)
\end{aligned}
$$

Substituting equations (14) and (20) in equation (31) and dividing both sides by $\left(t_{\mathrm{db}, \mathrm{i}}-t_{\mathrm{wb}, \mathrm{i}}\right)$, after some simplification and use of a direction indicator for water $\left(i_{\mathrm{w}}= \pm 1\right)$, the following is obtained

$$
\frac{\mathrm{d} \Theta_{\mathrm{w}}}{\mathrm{d} X}=\frac{i_{\mathrm{w}}}{C}\left[\Theta_{\mathrm{a}}+H \xi_{\mathrm{a}}-(1+L e B H) \Theta_{\mathrm{w}}\right]
$$

where

$$
C=\frac{\dot{m}_{\mathrm{w}} c_{\mathrm{p}, \mathrm{w}}}{\dot{m}_{\mathrm{a}} c_{\mathrm{p}, \mathrm{a}}}
$$

and

$$
H=\frac{\left(h_{\mathrm{fg}, \mathrm{w}}-h_{\mathrm{f}, \mathrm{w}}\right)}{h_{\mathrm{fg}, \mathrm{wb}}}
$$

The direction indicator has a positive sign for the parallel flow and a negative sign for the counterflow. It is important to note that no such indicator is required for the air, as it always flows in an upward direction.

The water-to-air heat capacity ratio can be calculated by using the water flow rate at the inlet. As with the terms $b$ and $B$, let $H$ be assumed to be known and constant. The procedure for finding the value of $H$ will be discussed in a later section. Thus, the original system of equations has now been transformed into a non-dimensional form without neglecting water evaporation. The final equations are (24), (30), and (32), where equations (24) and (30) describe the heat- and mass-transfer process between the air and water and equation (32) is the water energy balance for an adiabatic evaporation process.

\section{CALCULATION OF PARAMETER $H$}

In Table 1, the 'improved non-dimensional model' represents the results of the current work. At present, two possible solutions are proposed to calculate the parameter $H$. In both methods, it is found that the cooling range must be $\geqslant 10{ }^{\circ} \mathrm{C}$ for the methods to be applicable. Furthermore, it was noted that for smaller cooling ranges, improvement in the prediction is not often required and that the original solution [11] suffices, and for such cases, the value of $H$ is taken as unity.

\subsection{Method 1}

Let the quantities in the numerator of equation (34) be evaluated at the inlet wet-bulb temperature. Therefore

$$
H=\frac{\left(h_{\mathrm{fg}, \mathrm{wb}}-h_{\mathrm{f}, \mathrm{wb}}\right)}{h_{\mathrm{fg}, \mathrm{wb}}}
$$

It is evident from Table 1 that this method allowed for a maximum decrease of 4.4 per cent in error (see no. 5.2) when compared with non-dimensional solution of Halasz [11].

\subsection{Method 2}

In the second method, an empirical relation was developed to calculate a representative water temperature to be used for evaluating the quantities in the numerator of equation (34). Using some sample problems, linear regression was used to evaluate the most important variables that predicted the required representative temperature. In this regard, it was found that the cooling range and mass flow ratio were the major factors involved. The final empirical equation based on several numerical experiments is given by

$$
t_{\mathrm{w}, \text { repr }}=\sqrt{\frac{3\left(t_{\mathrm{w}, \mathrm{i}}-t_{\mathrm{w}, \mathrm{o}}\right)^{2}}{m_{\text {ratio }}^{0.7}}}
$$

It can be seen clearly from Table 1 that there is a marked decrease in error for all cases where the cooling range is $>10{ }^{\circ} \mathrm{C}$, especially in those cases where the cooling range is very large. Furthermore, the maximum error was calculated to be 3.3 and 6.8 per cent when the inlet air was unsaturated and saturated, respectively. 


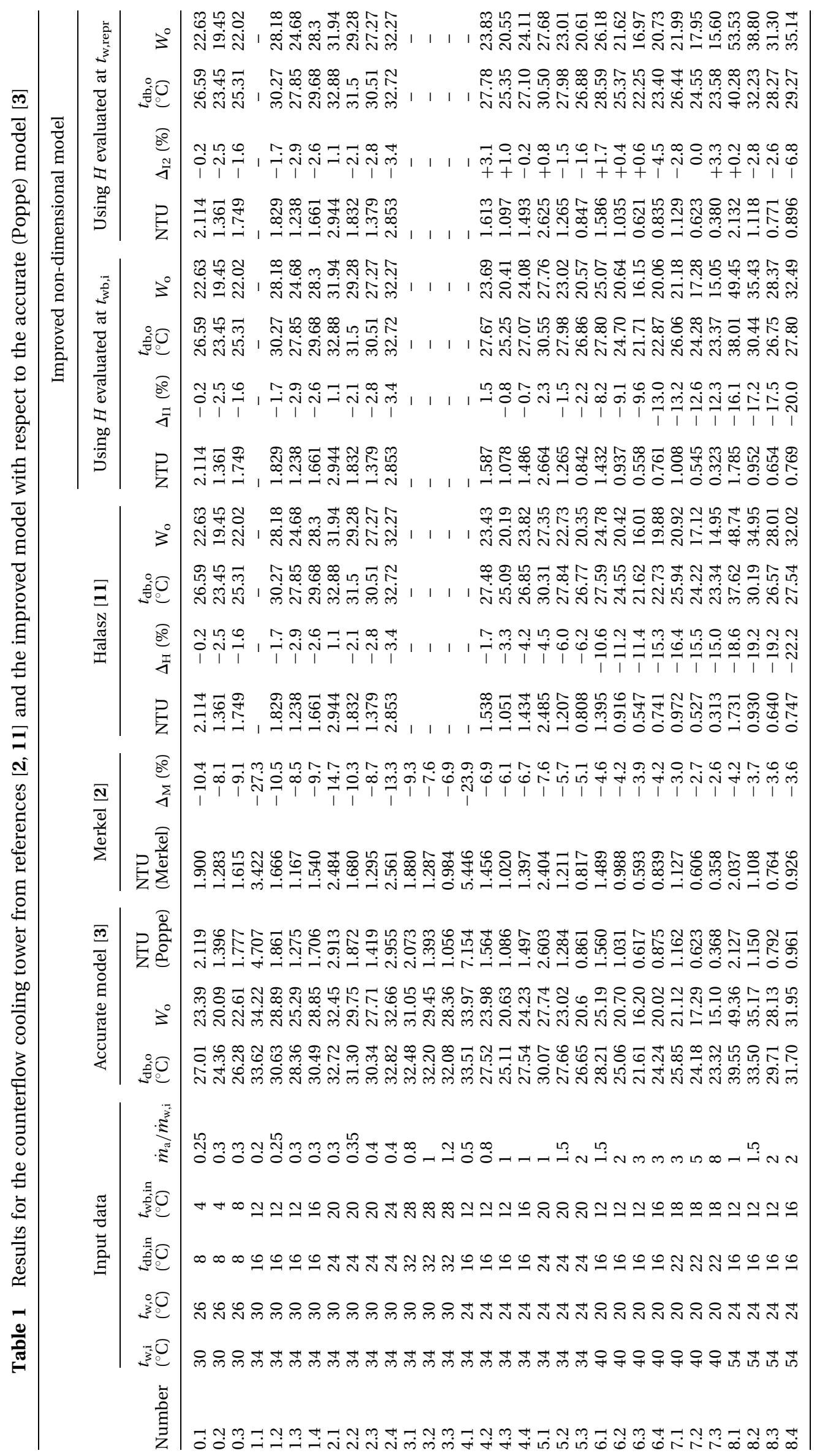




\section{CASE STUDY: COUNTERFLOW WET-COOLING TOWER}

In this case, water flows in a downward direction, and therefore, the ordinary differential equations, with the directional indicator $i_{\mathrm{w}}=-1$ and Lewis relation equal to unity, the non-dimensional equations reduce to

$$
\begin{aligned}
\frac{d \xi_{\mathrm{a}}}{\mathrm{d} X} & =-\xi_{\mathrm{a}}+B \Theta_{\mathrm{w}} \\
\frac{\mathrm{d} \Theta_{\mathrm{a}}}{\mathrm{d} X} & =\left(\Theta_{\mathrm{w}}-\Theta_{\mathrm{a}}\right) \\
\frac{\mathrm{d} \Theta_{\mathrm{w}}}{\mathrm{d} X} & =-\frac{1}{C} \Theta_{\mathrm{a}}-\frac{H}{C} \xi_{\mathrm{a}}+\frac{(1+B H)}{C} \Theta_{\mathrm{w}}
\end{aligned}
$$

Although the boundary conditions are the same as used in reference [11], these are shown here again for convenience (Fig. 3). It should be noted that only equation (39) is different from the set of ordinary differential equations derived by Halasz [11].

The general solution of the aforementioned system of differential equations is given by

$$
\begin{aligned}
& \Theta_{\mathrm{a}}=C_{0,1}+\frac{C}{1+B H} C_{0,2} \mathrm{e}^{m_{2} X}+H C_{0,3} \mathrm{e}^{-X} \\
& \xi_{\mathrm{a}}=B C_{0,1}+\frac{B C}{1+B H} C_{0,2} \mathrm{e}^{m_{2} X}-C_{0,3} \mathrm{e}^{-X} \\
& \Theta_{\mathrm{w}}=C_{0,1}+C_{0,2} \mathrm{e}^{m_{2} X}
\end{aligned}
$$

where

$$
m_{2}=\frac{(1+B H)}{C}-1
$$

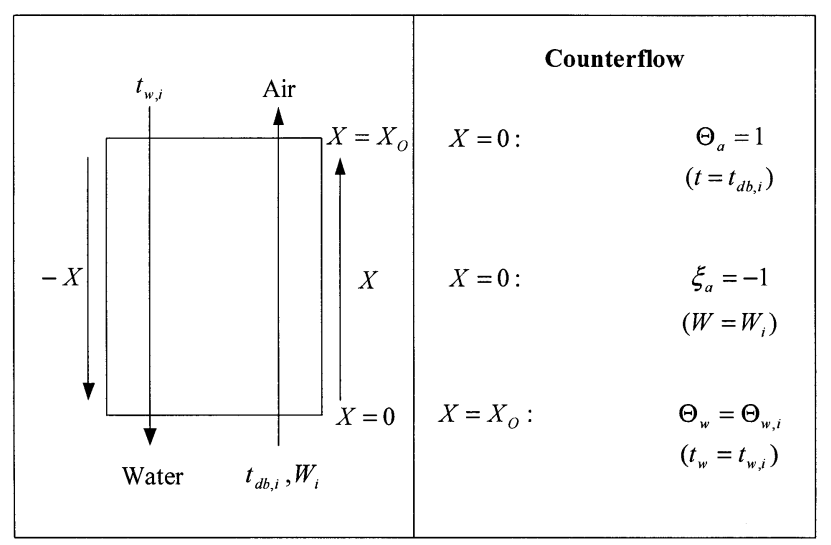

Fig. 3 Boundary conditions for counterflow wet-cooling tower
Substituting the boundary conditions (Fig. 3) in the aforementioned equations

$$
\left[\begin{array}{ccc}
1 & \frac{C}{1+B H} & H \\
B & \frac{B C}{1+B H} & -1 \\
1 & \mathrm{e}^{m_{2} X_{0}} & 0
\end{array}\right] \cdot\left[\begin{array}{c}
C_{0,1} \\
C_{0,2} \\
C_{0,3}
\end{array}\right]=\left[\begin{array}{c}
1 \\
-1 \\
\Theta_{\mathrm{w}, \mathrm{i}}
\end{array}\right]
$$

By inspection, the parameter $z$ can now be represented by

$$
z=\frac{(1+B H)}{C}
$$

which is defined as the ratio of the corrected total (i.e. sensible + latent) heat capacity rate of the mass flow rate of air along its saturation line to the heat capacity rate of the water mass flow rate.

Using the parameter $z$, the cooling tower efficiency can be expressed as

$$
\begin{aligned}
\varepsilon & =\frac{t_{\mathrm{w}, \mathrm{i}}-t_{\mathrm{w}, \mathrm{o}}}{t_{\mathrm{w}, \mathrm{i}}-t_{\mathrm{wb}, \mathrm{i}}}=1-\frac{\Theta_{\mathrm{w}, \mathrm{o}}}{\Theta_{\mathrm{w}, \mathrm{i}}} \\
& =z \frac{1-\mathrm{e}^{-(1-z) X_{\mathrm{o}}}}{1-z \mathrm{e}^{-(1-z) X_{\mathrm{o}}}}\left[\frac{H-1}{\Theta_{\mathrm{w}, \mathrm{i}}(1+B H)}+1\right]
\end{aligned}
$$

If we substitute $H=1$ in equation (46), it reduces to the expression for efficiency originally derived by Halasz [11].

It should be noted that the aforementioned set of equations are to be used if the complete process (or operating) line is required. Otherwise, if only the outlet conditions are required, then simpler equations that are discussed in the following section can be used.

\subsection{Calculating outlet air conditions}

Once the non-dimensional model is adjusted to the actual process, the dimensionless outlet air temperature and humidity ratio can be directly calculated from the equations given subsequently (refer to the Appendix 2 for additional details)

$$
\begin{aligned}
\Theta_{\mathrm{a}, \mathrm{o}}= & \frac{1-H}{1+B H}+\frac{\Theta_{\mathrm{w}, \mathrm{i}} \varepsilon}{z}+H\left[\frac{1+B}{1+B H}\right] \mathrm{e}^{-X_{\mathrm{o}}} \\
= & \frac{1-H}{1+B H}+\frac{C}{1+B H}\left(\Theta_{\mathrm{w}, \mathrm{i}}-\Theta_{\mathrm{w}, \mathrm{o}}\right) \\
& +H\left[\frac{1+B}{1+B H}\right] \mathrm{e}^{-X_{\mathrm{o}}} \\
\xi_{\mathrm{a}, \mathrm{o}}= & B\left[\frac{1-H}{1+B H}\right]+\frac{B \Theta_{\mathrm{w}, \mathrm{i}} \varepsilon}{z}-\left[\frac{1+B}{1+B H}\right] \mathrm{e}^{-X_{\mathrm{o}}} \\
= & B\left[\frac{1-H}{1+B H}\right]+\frac{B C}{1+B H}\left(\Theta_{\mathrm{w}, \mathrm{i}}-\Theta_{\mathrm{w}, \mathrm{o}}\right) \\
& -\left[\frac{1+B}{1+B H}\right] \mathrm{e}^{-X_{0}}
\end{aligned}
$$


The dimensional outlet dry-bulb temperature and humidity ratio can be calculated from the present improved model by using the following set of equations

$$
\begin{aligned}
t_{\mathrm{db}, \mathrm{o}}= & t_{\mathrm{wb}, \mathrm{i}}+\left[\frac{1-H}{1+B H}\left(t_{\mathrm{db}, \mathrm{i}}-t_{\mathrm{wb}, \mathrm{i}}\right)+\frac{\left(t_{\mathrm{w}, \mathrm{i}}-t_{\mathrm{w}, \mathrm{o}}\right)}{z}\right. \\
& \left.+H\left[\frac{1+B}{1+B H}\right]\left(t_{\mathrm{db}, \mathrm{i}}-t_{\mathrm{wb}, \mathrm{i}}\right) \mathrm{e}^{-X_{\mathrm{o}}}\right] \\
W_{\mathrm{o}}= & W_{\mathrm{s}, \mathrm{wb}}+\left(W_{\mathrm{s}, \mathrm{wb}}-W_{\mathrm{i}}\right)\left[B\left[\frac{1-H}{1+B H}\right]\right. \\
& \left.+\frac{B}{z} \frac{\left(t_{\mathrm{w}, \mathrm{i}}-t_{\mathrm{w}, \mathrm{o}}\right)}{\left(t_{\mathrm{db}, \mathrm{i}}-t_{\mathrm{wb}, \mathrm{i}}\right)}-\left[\frac{1+B}{1+B H}\right] \mathrm{e}^{-X_{\mathrm{o}}}\right]
\end{aligned}
$$

As in Halasz's model [11], the dimensionless temperature and humidity ratio are undetermined for the case of air saturated at the inlet because $\left(t_{\mathrm{db}, \mathrm{i}}-\right.$ $\left.t_{\mathrm{wb}, \mathrm{i}}\right)=0$ and $\left(W_{\mathrm{s}, \mathrm{wb}}-W_{\mathrm{i}}\right)=0$. Still, the dimensional values of these quantities can be calculated by

$$
\begin{aligned}
& t_{\mathrm{db}, \mathrm{o}}=t_{\mathrm{wb}, \mathrm{i}}+\left[\frac{\varepsilon}{z}\left(t_{\mathrm{w}, \mathrm{i}}-t_{\mathrm{wb}, \mathrm{i}}\right)\right] \\
& W_{\mathrm{o}}=W_{\mathrm{s}, \mathrm{wb}}+b\left(t_{\mathrm{db}, \mathrm{o}}-t_{\mathrm{wb}, \mathrm{i}}\right)
\end{aligned}
$$

It is important to understand that, in this case, the first term in brackets of equation (46) will be reduced to zero because of the non-dimensional water temperature term so that the efficiency of the system would be calculated by an expression similar to that of Halasz [11]. The difference lies in the fact that $z$ would still be calculated by equation (45).

It is again noted that if $H$ is taken as unity in equations (37) to (50), the solution originally derived by Halasz [11] is obtained. It is further seen that, for the case of air saturated at the inlet, the expressions obtained are the same as that derived earlier by Halasz [11].

\section{EFFECT ON PROCESS LINE}

Run 6.3 of Table 1 is used to illustrate the effect of $H$ on the air and water process (operating) lines. It can be seen from Fig. 4(a) that the use of the empirical equation (i.e. Method 2) has a marked effect on all process lines except the saturated humidity ratio $\left(W_{\mathrm{s}, \mathrm{w}}\right)$, which, in this case, overlaps the saturated humidity ratio line computed from Method 1. It should be kept in mind that the saturated humidity ratio was calculated from equation (19) and that $X$ does not necessarily correspond to the physical height of the cooling tower in this figure. All process (operating) lines are further compared with the distribution obtained from an accurate dimensional model of cooling towers and it is seen that both methods used to obtain $H$ in the improved model, (a) Actual temperature $\left({ }^{\circ} \mathrm{C}\right)$

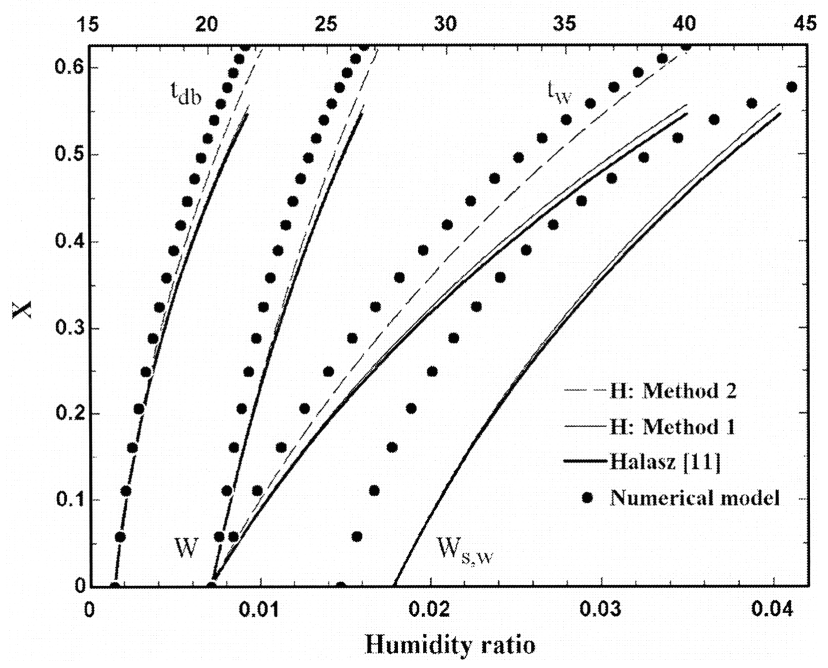

(b)

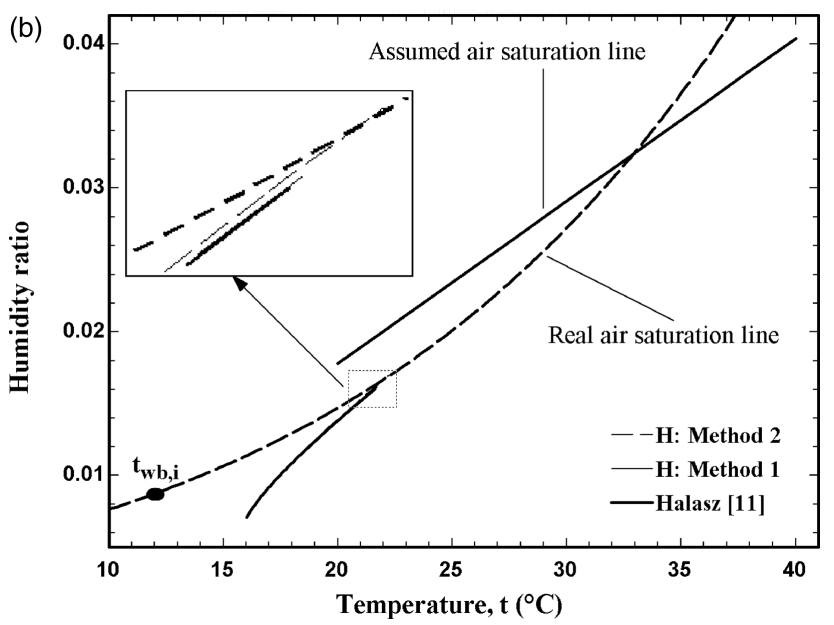

Fig. 4 Comparison of (a) the distribution of relevant process lines and (b) the air process line on the pychrometric chart (for run 6.3 refer to Table 1)

explained in the current work, provide a more accurate solution when compared with the original one given by Halasz [11]. Furthermore, the dimensional values of the air process line were plotted on the psychrometric chart along with the straight airsaturation line (See Fig. 4(b)). It should be noted that as the variable $H$ does not affect the assumed straight air-saturation line, it is the same in all the cases presented in the figure.

\section{CONCLUDING REMARKS}

It is important to emphasize that the improved nondimensional model covers the tower range of $10^{\circ} \mathrm{C}$ or higher, where the error varied from 1 to 22 per cent when the original non-dimensional model was 
used. Two possible solutions are presented to evaluate the new variable $H$ to reduce this error, the amount of which depends on the method used. The results from the improved model indicate that both are effective in decreasing the error in prediction of the NTU, but the empirical equation (Method 2) is comparatively better at higher ranges. We believe this is an important and useful step towards a more accurate analytical solution regarding evaporative heat exchangers. It is further understood that the approximation of the real saturation line by a straight line constitutes the biggest assumption in the model and can probably be neglected to a large extent by breaking the real saturation line into smaller parts where each of these can then be represented by a straight line and then solved by marching from the inlet to outlet water temperatures.

\section{ACKNOWLEDGEMENTS}

The authors acknowledge the support provided by King Fahd University of Petroleum and Minerals through the research project (ME/RISK-FOULING/230).

\section{REFERENCES}

1 Walker, W. H., Lewis, W. K., McAdams, W. H., and Gilliland, E. R. Principles of chemical engineering, 3rd edition, 1923 (McGraw-Hill Inc., New York).

2 Merkel, F. Verdunstungshuhlung. Zeitschrift des Vereines Deutscher Ingenieure (V.D.I.), 1925, 70, $123-128$.

3 Poppe, M. Wärme- und Stoffübertragung bei der Verdunstungskühlung im Gegen- und Kreuzstrom. VDI - Forschungsheft, 1973, 38(560), 1-44.

4 Webb, R. L. A unified theoretical treatment for thermal analysis of cooling towers, evaporative condensers, and fluid coolers. ASHRAE Trans., 1984, 90(Part 2), 398-415.

5 Webb, R. L. and Villacres, A. Performance simulation of evaporative heat exchangers (cooling towers, fluid coolers and condensers). Heat Transfer Eng., 1985, 6(2), 31-38.

6 Mohiuddin, A. K. M. and Kant, K. Knowledge base for the systematic design of wet cooling towers. Part I: selection and tower characteristics. Int. J. Refrig., 1996, 19(1), 43-51.

7 Mohiuddin, A. K. M. and Kant, K. Knowledge base for the systematic design of wet cooling towers. Part II: fill and other design parameters. Int. J. Refrig., 1996, $19(1), 52-60$

8 El-Dessouky, H. T. A., Al-Haddad, A., and Al-Juwayhel, F. A modified analysis of counter flow cooling towers. ASME J. Heat Transfer, 1997, 119(3), 617-626.

9 Khan, J. R. and Zubair, S. M. An improved design and rating analyses of counter flow wet cooling towers. ASME J. Heat Transfer, 2001, 123(4), 770-778.

10 Halasz, B. General mathematical model of evaporative cooling devices. Rev. Gen. Therm., 1998, 37(4), 245-255.

11 Halasz, B. Application of a general non-dimensional mathematical model to cooling towers. Int. J. Therm. Sci., 1999, 38, 75-88.

12 Parker, R. O. and Treybal, R. E. The heat, mass transfer characteristics of evaporative coolers. AIChE Chem. Eng. Prog. Symp. Ser, 1961, 57(32), 138-149.

13 Kuehn, T. H., Ramsey, J. W., and Threlkeld, J. L. Thermal environmental engineering, 3rd edition, 1998 (Prentice-Hall Inc., New Jersey).

\section{APPENDIX 1}

\section{Notation}

A

$b$

$B$

$c_{\mathrm{p}}$

C

$C_{0, j}$

$h$

$h_{\mathrm{c}}$

$h_{\mathrm{D}}$

$h_{\mathrm{j}}$

$h_{f g}$

$h_{g}$

$h_{g}^{0}$

Le

$m_{\text {ratio }}$

$\dot{m}$

NTU

$P$

$t$

W

$X$

$z$

$\Delta_{\mathrm{M}}$

$\Delta_{\mathrm{H}}$ overall surface area of water-air interface, $\mathrm{m}^{2}$ slope of straight air-saturation line (see equations (18) and (19)), $1 /{ }^{\circ} \mathrm{C}$ parameter defined in equation (21) specific heat at constant pressure, $\mathrm{kJ} / \mathrm{kg}_{\mathrm{a}}$ per C

heat capacity ratio of water to air constant of integration $(j=1,2,3)$ in equations (40) to (42) enthalpy of moist air, $\mathrm{kJ} / \mathrm{kg}_{\mathrm{a}}$ convective heat-transfer coefficient of air, $\mathrm{kW} / \mathrm{m}^{2}$ per $\mathrm{C}$

convective mass-transfer coefficient, $\mathrm{kg}_{\mathrm{w}} / \mathrm{m}^{2}$ per s specific enthalpy of saturated liquid water, $\mathrm{kJ} / \mathrm{kg}_{\mathrm{w}}$ change-of-phase enthalpy, $\mathrm{kJ} / \mathrm{kg}_{\mathrm{w}}$ specific enthalpy of saturated water vapour, $\mathrm{kJ} / \mathrm{kg}_{\mathrm{w}}$ specific enthalpy of saturated water vapour evaluated at $0{ }^{\circ} \mathrm{C}, \mathrm{kJ} / \mathrm{kg}_{\mathrm{w}}$ Lewis relation ( $\left.L e=h_{\mathrm{D}} c_{\mathrm{p}, \mathrm{a}} / h_{\mathrm{c}}\right)$ water-to-air mass flow rate ratio $\left(=\dot{m}_{\mathrm{w}, \mathrm{i}} / \dot{m}_{\mathrm{a}}\right)$ mass flow rate, $\mathrm{kg}_{\mathrm{a}} / \mathrm{s}$ number of transfer units pressure, $\mathrm{kPa}$ dry-bulb temperature of moist air, ${ }^{\circ} \mathrm{C}$ humidity ratio of moist air, $\mathrm{kg}_{\mathrm{w}} / \mathrm{kg}_{\mathrm{a}}$ non-dimensional parameter defined in equation (16) non-dimensional parameter defined in equation (45)

percentage error in NTU prediction by Merkel's model with respect to Poppe's model (per cent) percentage error in NTU prediction by Halasz model with respect to Poppe's model (per cent) 
$\Delta_{\mathrm{I} 1} \quad$ percentage error in NTU prediction by Method 1 of the present improved non-dimensional model with respect to Poppe's model (per cent)

$\Delta_{\mathrm{I} 2} \quad$ percentage error in NTU prediction by Method 2 of the present improved non-dimensional model with respect to Poppe's model (per cent)

$\varepsilon \quad$ efficiency of cooling tower

$\Theta \quad$ non-dimensional temperature defined in equation (12)

$\xi \quad$ non-dimensional humidity ratio defined in equation (13)

\section{Subscripts}

$\begin{array}{ll}\text { a } & \text { (moist) air } \\ \text { da } & \text { dry air } \\ \text { db } & \text { dry-bulb } \\ \text { g,w } & \text { vapour at water temperature } \\ \text { i } & \text { inlet } \\ \text { int } & \text { on the air-water interface surface } \\ \text { L } & \text { linear } \\ \text { m } & \text { mean } \\ \text { max } & \text { maximum } \\ \text { o } & \text { outlet } \\ \text { O } & \text { overall value } \\ \text { repr } & \text { representative value } \\ \text { R } & \text { real } \\ \text { s,w } & \text { saturated moist air at water temperature } \\ \text { w } & \text { water } \\ \text { wb } & \text { wet-bulb }\end{array}$

\section{APPENDIX 2}

\section{Derivation of equations (47) and (48)}

First, solving the matrix represented by equation (44), the constants $C_{0,1}, C_{0,2}$, and $C_{0,3}$ are calculated as

$$
\begin{aligned}
C_{0,1} & =\frac{z \mathrm{e}^{m_{2} X_{\mathrm{O}}}(H-1)+\Theta_{\mathrm{w}, \mathrm{i}}(1+B H)}{(1+B H)\left(1-z \mathrm{e}^{m_{2} X_{\mathrm{O}}}\right)} \\
C_{0,2} & =\frac{z\left(H-1+\Theta_{\mathrm{w}, \mathrm{i}}(1+B H)\right)}{(1+B H)\left(z \mathrm{e}^{m_{2} X_{\mathrm{O}}}-1\right)} \\
C_{0,3} & =\frac{1+B}{1+B H}
\end{aligned}
$$

Now, evaluating equation (42) at $X=X_{\mathrm{O}}$ and $X=0$ and then subtracting the result

$$
C_{0,2} \mathrm{e}^{m_{2} X_{\mathrm{o}}}=\Theta_{\mathrm{w}, \mathrm{i}}-\Theta_{\mathrm{w}, \mathrm{o}}+C_{0,2}
$$

Substituting equations (54) and (45) into equations
(40) and (41)

$$
\begin{aligned}
\Theta_{\mathrm{a}} & =C_{0,1}+\frac{\Theta_{\mathrm{w}, \mathrm{i}}-\Theta_{\mathrm{w}, \mathrm{o}}}{z}+\frac{C_{0,2}}{z}+H C_{0,3} \mathrm{e}^{-X} \\
\xi_{\mathrm{a}} & =B C_{0,1}+\frac{B\left(\Theta_{\mathrm{w}, \mathrm{i}}-\Theta_{\mathrm{w}, \mathrm{o}}\right)}{z}+B \frac{C_{0,2}}{z}-C_{0,3} \mathrm{e}^{-X}
\end{aligned}
$$

Now the following quantity holds

$$
C_{0,1}+\frac{C_{0,2}}{z}=\frac{1-H}{1+B H}
$$

Substituting equation (57) into equations (55) and (56) and evaluating at $X=X_{\mathrm{O}}$, after some simplification, the following outlet air conditions are obtained

$$
\begin{aligned}
\Theta_{\mathrm{a}, \mathrm{o}} & =\frac{1-H}{1+B H}+\frac{\Theta_{\mathrm{w}, \mathrm{i}}-\Theta_{\mathrm{w}, \mathrm{o}}}{z}+H\left[\frac{1+B}{1+B H}\right] \mathrm{e}^{-X_{\mathrm{O}}} \\
\xi_{\mathrm{a}, \mathrm{o}} & =B\left[\frac{1-H}{1+B H}\right]+\frac{B\left(\Theta_{\mathrm{w}, \mathrm{i}}-\Theta_{\mathrm{w}, \mathrm{o}}\right)}{z}-\left[\frac{1+B}{1+B H}\right] \mathrm{e}^{-X_{\mathrm{o}}}
\end{aligned}
$$

It is noted that equations (58) and (59) are the same as equations (47) and (48).

\section{APPENDIX 3}

\section{Approximation of linear saturation line}

Halasz [10] explained that the value of the parameter $B$ is considered known and constant and that this parameter is a function of the inlet wet-bulb temperature, a representative water temperature and air saturation data. This is clear that for the relationship to be valid in the non-dimensional domain, it must be adjusted to the real air-saturation data to yield the final results. Halasz [11] further explained that, for an assumed straight air-saturation line, the following holds

$$
\frac{h_{\mathrm{D}} A}{\dot{m}_{\mathrm{w}} c_{\mathrm{p}, \mathrm{w}}}=\int_{0}^{A} \frac{h_{\mathrm{D}} \mathrm{d} A}{\dot{m}_{\mathrm{w}} c_{\mathrm{p}, \mathrm{w}}}=\int_{t_{\mathrm{w}, \mathrm{o}}}^{t_{\mathrm{w}, \mathrm{i}}} \frac{\mathrm{d} t_{\mathrm{w}}}{h_{\mathrm{s}, \mathrm{w}}-h}
$$

It is important to note that the basic idea is to obtain an 'equivalent' straight air saturation line that produces the same integral on the RHS of the aforementioned equation as from a real saturation line. Although this assumption has an effect on the cooling tower process and would cause a slightly different distribution of the air enthalpy along the surface, it is assumed that $h$ is the 
Table 2 Polynomial coefficients for equation (63) for a total pressure of 1 bar

\begin{tabular}{lcccl}
\hline$t_{\mathrm{w}}\left({ }^{\circ} \mathrm{C}\right)$ & $a_{0}$ & $a_{1}$ & \multicolumn{1}{c}{$a_{2}$} & \multicolumn{1}{c}{$a_{3}$} \\
\hline $5<t_{\mathrm{w}} \leqslant 20$ & -0.672969 & 10.0723 & 0.756563 & 0.0143143 \\
$20<t_{\mathrm{w}} \leqslant 40$ & -294.945 & 48.4703 & -0.952424 & 0.040481 \\
$40<t_{\mathrm{w}} \leqslant 60$ & -7020.16 & 520.79 & -12.0867 & 0.128689 \\
\hline
\end{tabular}

function of $t_{\mathrm{w}}$ in both saturation lines. Therefore

$$
\int_{t_{\mathrm{w}, \mathrm{o}}}^{t_{\mathrm{w}, \mathrm{i}}}\left(h_{\mathrm{s}, \mathrm{w}}\right)_{\mathrm{L}} \mathrm{d} t_{\mathrm{w}}=\int_{t_{\mathrm{w}, \mathrm{o}}}^{t_{\mathrm{w}, \mathrm{i}}}\left(h_{\mathrm{s}, \mathrm{w}}\right)_{\mathrm{R}} \mathrm{d} t_{\mathrm{w}}
$$

The real enthalpy of the saturated air is a known function of water temperature. That is

$$
\mathfrak{I}=\int_{t_{\mathrm{w}, \mathrm{o}}}^{t_{\mathrm{w}, \mathrm{i}}}\left(h_{\mathrm{s}, \mathrm{w}}\right)_{\mathrm{R}} \mathrm{d} t_{\mathrm{w}}=\Im\left(t_{\mathrm{w}, \mathrm{i}}\right)-\Im\left(t_{\mathrm{w}, \mathrm{o}}\right)
$$

where the values of the functions on the RHS can be read from Table 1 of reference [11]. The following polynomial equation can also be used (see Table 2 for coefficient values)

$$
\Im\left(t_{\mathrm{w}}\right)=a_{0}+a_{1} t_{\mathrm{w}}+a_{2} t_{\mathrm{w}}^{2}+a_{3} t_{\mathrm{w}}^{3}
$$

It should be noted that the effect of elevation can be taken into account by integrating equation (62) using appropriate values of $h_{\mathrm{s}, \mathrm{w}}\left(t_{\mathrm{w}}, P\right)$. Now, the straight air-saturation line is expressed by combining equations (19) and (25) giving

$$
\left(h_{\mathrm{s}, \mathrm{w}}\right)_{\mathrm{L}}=c_{\mathrm{p}, \mathrm{da}} t_{\mathrm{w}}+\left\{W_{\mathrm{s}, \mathrm{wb}}+b\left(t_{\mathrm{w}}-t_{\mathrm{wb}, \mathrm{i}}\right)\right\}\left(h_{\mathrm{g}}^{0}+c_{\mathrm{p}, \mathrm{v}} t_{\mathrm{w}}\right)
$$

Substituting equation (23) into equation (64) and then substituting the resulting equation into the LHS of equation (61) and considering $t_{\mathrm{w}, \mathrm{m}}$ as the arithmetic mean of the inlet and outlet water temperatures, the final expression for the parameter $b$ reduces to

$$
b=\frac{\left(\Im\left(t_{\mathrm{w}, \mathrm{i}}\right)-\Im\left(t_{\mathrm{w}, \mathrm{o}}\right)\right) /\left(t_{\mathrm{w}, \mathrm{i}}-t_{\mathrm{w}, \mathrm{o}}\right)-\left(W_{\mathrm{s}, \mathrm{wb}} h_{\mathrm{g}}^{0}+c_{\mathrm{p}, \mathrm{a}} t_{\mathrm{w}, \mathrm{m}}\right)}{c_{\mathrm{p}, \mathrm{v}}\left(\left(4 t_{\mathrm{w}, \mathrm{m}}^{2}-t_{\mathrm{w}, \mathrm{i}} t_{\mathrm{w}, \mathrm{o}}\right) / 3-t_{\mathrm{wb}, \mathrm{i}} t_{\mathrm{w}, \mathrm{m}}\right)+h_{\mathrm{g}}^{0}\left(t_{\mathrm{w}, \mathrm{m}}-t_{\mathrm{wb}, \mathrm{i}}\right)}
$$

It should be emphasized that there are three limitations because of the linearization of the saturation line. First, the error would be significant for the case of a very large cooling range; secondly, the model could not describe cooling tower operation with a very small airflow; thirdly, the air was assumed to be unsaturated or, as a limiting case, saturated without fog. 